\title{
CORRECTION
}

\section{Correction: Bevacizumab-induced hypertension and proteinuria: a genome-wide study of more than 1000 patients}

Julia C. F. Quintanilha, Jin Wang, Alexander B. Sibley (D, Chen Jiang, Amy S. Etheridge, Fei Shen, Guanglong Jiang, Flora Mulkey, Jai N. Patel, Daniel L. Hertz, Elizabeth Claire Dees, Howard L. McLeod, Monica Bertagnolli, Hope Rugo, Hedy L. Kindler, William Kevin Kelly, Mark J. Ratain, Deanna L. Kroetz, Kouros Owzar, Bryan P. Schneider, Danyu Lin and Federico Innocenti (D

(c) The Author(s), under exclusive licence to Springer Nature Limited 2021

British Journal of Cancer (2022) 126:162; https://doi.org/10.1038/s41416-021-01617-1

Correction to: British Journal of Cancer https://doi.org/10.1038/ s41416-021-01557-w, published online 06 October 2021

The original version of this article unfortunately contained a mistake in an author affiliation. Dr. Kouros Owzar was listed as
"Department of Medicine, Indiana University School of Medicine, Indianapolis, IN, USA", when it should be "Duke Cancer Institute, Duke University Medical Center, Durham, NC, USA". The original article has been corrected. 